\title{
A Influência de Valores Ambientais e Organizacionais sobre a Aprendizagem Organizacional na Indústria Alimentícia Paranaense
}

\author{
Edson Ronaldo Guarido Filho \\ Clóvis L. Machado-da-Silva
}

\section{RESUMO}

O objetivo deste estudo foi verificar a influência de valores ambientais e organizacionais sobre a aprendizagem organizacional em empresas do setor de alimentos no Estado do Paraná. Para tanto, a presente pesquisa procura integrar elementos cognitivos, culturais e institucionais na investigação da natureza desse fenômeno enquanto processo articulado no contexto social que envolve o conjunto das organizações. Dados primários e secundários foram coletados e tratados mediante uso de procedimentos de análise de agrupamento e de variância, com o propósito de explorar diferenças entre grupos de empresas com distintos contextos institucionais de referência, no que concerne aos atributos e valores do arquétipo de aprendizagem. Os resultados indicam que empresas com contexto institucional de referência de nível internacional apresentam maior grau de presença das características do arquétipo, revelando a dinâmica de relacionamento entre o plano da ação e o plano institucional, em que a aprendizagem organizacional pode ser compreendida enquanto meio e resultado recursivamente construídos.

Palavras-chaves: mudança organizacional; aprendizagem organizacional; contexto institucional; valores ambientais; valores organizacionais.

\begin{abstract}
This study has been carried out to evaluate the influence of environmental and organizational values upon organizational learning in companies of the food industry in the State of Paraná, Brazil. As such this research incorporates cognitive, cultural and institutional aspects into the investigation of the nature of this phenomenon as an articulated process in the social context embracing all organizations. Aiming to differentiate among groups of companies with distinctive institutional contexts of reference, regarding the attributes and values of a constructed learning organization archetype, primary and secondary data were collected and processed by means of cluster and variance analyses. The results indicate that companies who possess institutional reference context at an international level showed higher presence of archetype characteristics, revealing the dynamic of the relationship between the plan of action and institutions, in which organizational learning can be understood as recursively constructed means and results.
\end{abstract}

Key words: organizational change; organizational learning; institutional context; environmental values; organizational values. 


\section{INTRODUÇÃO}

A globalização da economia e dos mercados que caracteriza a expansão do capitalismo em nível mundial, no final do segundo e início do terceiro milênios, vem provocando mudanças profundas e perturbadoras em praticamente todas as esferas da sociedade contemporânea. No mundo globalizado, a habilidade organizacional de lidar com as pressões ambientais vem sendo crescentemente valorizada, passando a ser compreendida como fator relevante para o desempenho e a própria sobrevivência das organizações. Nesse contexto, a aprendizagem organizacional passa a ser requisito não ocasional mas necessidade contínua e fundamental.

Inúmeros textos sobre aprendizagem organizacional surgiram na literatura especializada, nos últimos anos. As diferentes bases ontológicas e epistemológicas em que se baseiam esses textos contribuíram para a diversidade das perspectivas existentes (Easterby-Smith, 1997). No entanto, foi a abordagem gerencial que consagrou a temática da aprendizagem ao propor programas de ação e de reorganização da estrutura das empresas, muitas vezes na forma de receituário, em face dos componentes incertos da concorrência global. Em essência, a perspectiva gerencial defende que para se construir uma organização que aprende é necessário criar uma estrutura que permita a geração, a transferência e a ampliação do conhecimento, seja com base em intensivos instrumentos de troca de informações ou com base em uma cultura forte, fundada sobre pressupostos de compartilhamento e de pluralidade.

Embora seja de interesse atentar para esse tipo de perspectiva, não se deve tratá-la com exclusividade. Nos atuais estudos organizacionais cresce a tendência de se associar o delineamento estrutural da organização com a sua cultura, o que possibilita descortinar preferências quanto ao comportamento organizacional sob a ótica dos valores de seus membros, em especial daqueles que detêm o domínio da organização. A idéia de domínio da organização por determinados membros remete à centralidade dos valores do grupo com poder para disseminar as suas províncias de significado, a fim de realizar os seus objetivos. Valores e objetivos do grupo dominante passam a ser tratados como valores e objetivos propriamente organizacionais. Tal afirmação é tanto mais verdadeira quanto mais integrada for a cultura da organização.

O raciocínio precedente chama a atenção para os valores organizacionais. No entanto, organizações não são entidades isoladas mas inseridas em um contexto 
sociocultural, o que torna relevante considerar, também, valores ambientais; bem como a interação entre estes e aqueles na estruturação da organização e na definição da sua capacidade de aprender. Atentar para valores ambientais implica visualizar o contexto institucional das organizações, o que significa utilizar perspectiva mais ampla no tratamento da temática cultural.

A noção de contexto institucional das organizações resulta de concepção mais elaborada e abrangente do ambiente, envolvendo não apenas a dimensão econômica mas também a sociocultural. Os conceitos de ambiente técnico e de ambiente institucional, oriundos da teoria institucional, evidenciam tal enriquecimento analítico. Assim, em conjunto com aspectos econômicos, regras institucionalizadas e um amplo sistema de crenças e de valores ambientais exercem influência sobre a atividade organizacional: "produtos, serviços, técnicas, políticas e funções institucionalizadas são poderosos mitos; muitas organizações se adaptam a eles cerimonialmente" (Meyer e Rowan, 1977, p. 340). Entre as implicações possíveis dessa perspectiva, sugere-se que as organizações não só competem pela disponibilidade de recursos e pelo mercado consumidor, mas também pela legitimidade contextual de suas ações e estratégias (DiMaggio e Powell, 1983). Logo, pode-se considerar que forças atreladas ao sistema de valores ambientais, ao afetarem o direcionamento estratégico da organização, também atuam no sentido de influenciar a dimensão estrutural da aprendizagem organizacional.

Em face do exposto, torna-se importante entender o papel dos valores do contexto institucional em sua relação com os valores organizacionais no sentido de definir padrões estruturais e estratégicos para as atividades da organização. Deste modo, tratar a aprendizagem organizacional sem dar a devida atenção à sua dimensão cultural seria reduzi-la a um receituário de práticas ou como simples expansão da aprendizagem individual. Nesse sentido, Cook e Yanow (1996) entendem que a aprendizagem organizacional como fenômeno próprio só pode ser compreendida sobre uma base cultural, isto é, no nível agregado, que é fundamentalmente distinto do processo de aprendizagem individual. "Pessoas vêm e vão, porém organizações preservam, de forma continuada, conhecimentos, comportamentos, mapas cognitivos, normas e valores" (Daft e Weick, 1984, p. 285).

A partir dessa perspectiva, procurou-se, neste estudo, verificar o fenômeno da aprendizagem organizacional na indústria de produtos alimentícios do Estado do Paraná, com base na influência de valores ambientais e organizacionais. A lógica de análise se fundamenta em uma visão integradora, que abrange aspectos culturais e institucionais, de modo que a aprendizagem organizacional possa ser compreendida não pontualmente, focada na solução de problemas específicos, mas como processo contínuo e culturalmente articulado no contexto social que engloba o conjunto das organizações. 


\section{Referencial Teórico}

A variedade presente nos estudos sobre aprendizagem organizacional (Weick e Westley, 1996) vem sendo discutida por diversos autores. Entre eles, Tsang (1997) classificou em três grandes grupos os trabalhos sobre o tema, com base no tratamento dado ao conceito: como fenômeno cognitivo, como fenômeno comportamental ou como fenômeno cultural. Independentemente da perspectiva pela qual se orientam esses pesquisadores, é notável a predominância de um enfoque estritamente interno à organização. Nessa linha de análise, Crossan et al. (1994) adotam o termo aprendizagem dentro das organizações. Estes autores, com o objetivo de integrar tais abordagens, consideram esquemas de significado individual em que se ressalta a intuição, a percepção e a interpretação, em associação com elementos simbólicos como a linguagem, de tal modo que constitua uma visão compartilhada da realidade, passível de ser institucionalizada na estrutura e nas estratégias da organização.

Sem tratar, aqui, de discutir o mérito e as limitações desses três grupos de trabalhos, entende-se que seja necessário contribuir para o debate sobre o tema mediante a ampliação do foco de análise. Constitui assertiva básica do presente estudo que a compreensão da lógica organizacional não deve ser dissociada de elementos de caráter cultural com origem no contexto institucional, os quais também exercem influência sobre a aprendizagem organizacional.

Em anos mais recentes, a teoria institucional, mais especificamente a sua vertente cognitiva, vem ganhando espaço no meio acadêmico. Sob a premissa de que valores institucionalizados na sociedade permeiam as formas organizacionais, destaca-se, nessa perspectiva, que a análise racional, aquela especificamente voltada para aspectos instrumentais, deve ser enriquecida com a consideração de componentes culturais e simbólicos intra e interorganizacionais nos estudos sobre organizações. Aceita-se, portanto, que pressupostos da realidade socialmente construída, com suporte em valores/crenças e conhecimentos compartilhados, definem comportamentos e estruturas adotados como corretos (Scott, 1995b).

Autores que adotam essa perspectiva enfatizam que toda situação social que perdure no tempo tem a tendência de ser institucionalizada, em face das necessidades de previsibilidade e de controle das ações humanas. Conforme Berger e Luckmann (1967), isso significa que, em um primeiro instante, as ações habituais tornam-se tipificações, ou seja, padrões de associação entre executores e tarefas executadas. Com a transmissão dessas tipificações, ao longo do tempo e das gerações, elas passam a ser objetivadas, isto é, aceitas como fatos inegáveis. 
Aquilo, portanto, que anteriormente se concebia como lá vamos nós de novo (o hábito), ganha caráter normativo, inerente ao sistema de conhecimento humano, atingindo o status do é assim que as coisas são feitas. Dessa forma, a criação de um conjunto de valores e conhecimentos compartilhados origina uma realidade socialmente construída, institucionalizada e legitimada na sociedade.

Ainda de acordo com Berger e Luckmann (1967), a construção do mundo institucional decorre de três momentos dialeticamente relacionados, que correspondem a uma caracterização da realidade social: (1) a exteriorização, em que a sociedade é tratada como produto humano; (2) a objetivação, em que se atribui à sociedade a qualidade de realidade objetiva; e (3) a interiorização, em que se entende o homem como produto social. Tal raciocínio revela um contexto cultural mais amplo, que se sobrepõe aos aspectos estritamente subjetivos, enfatizando o processo de interação social que forma as bases do conhecimento institucionalizado. Assim, a institucionalização representa um processo condicionado pela lógica da conformidade às normas socialmente aceitas, bem como pela incorporação de um sistema de conhecimento construído ao longo da interação social, os quais constituem parâmetros para a concepção de realidade dos atores sociais, definindo, portanto, o seu modo de agir. Em busca de legitimação e de aceitação social, as organizações procuram conformar as suas ações e estruturas aos valores ambientais e aos conceitos considerados socialmente corretos (Scott, 1991).

A adequação aos requisitos ambientais aceitos como padrões legítimos é oportunidade para assegurar o reconhecimento social da organização, melhorar seu relacionamento com a sociedade e reduzir riscos em momentos turbulentos, ao longo da sua história. A conformidade aumenta suas chances de sobrevivência, ao que parece em grau maior do que a eficácia ou o desempenho imediato dos procedimentos e estratégias (Meyer e Rowan, 1977; Machado-da-Silva e Fonseca, 1993).

Esse tipo de conformidade é reproduzido a partir de três mecanismos de isomorfismo institucional: o coercitivo, o normativo e o mimético. $\mathrm{O}$ isomorfismo coercitivo resulta de pressões formais e informais exercidas por uma organização sobre outra que se encontra em situação de dependência; o isomorfismo mimético decorre de problemas tecnológicos, objetivos conflitantes e exigências ambientais, levando a organização a imitar procedimentos bem sucedidos implementados por outras organizações; o isomorfismo normativo refere-se à profissionalização, mediante a especialização dos membros de segmentos ocupacionais, que define as condições e métodos de trabalho (DiMaggio e Powell, 1983; Machado-da-Silva e Fonseca, 1993).

Nessa linha de análise, a noção de ambiente é decomposta ao se reconhecer a existência de duas facetas da mesma dimensão contextual: o ambiente técnico e 
o ambiente institucional. $\mathrm{O}$ ambiente técnico caracteriza-se pela troca de bens e serviços, no qual as organizações são avaliadas por critérios de eficiência e de eficácia. $\mathrm{O}$ ambiente institucional distingue-se pela existência de regras e exigências sociais às quais as organizações devem se adequar (Scott, 1992). O primeiro representa os "espaços de competição na ótica econômica [enquanto o segundo] proporciona às organizações legitimidade e suporte contextual" (Machado-daSilva e Fonseca, 1996, p. 103-104).

Cabe ressaltar que a conformidade ao contexto institucional não implica em imobilismo social ou plena homogeneidade, uma vez que as condições ambientais são percebidas e interpretadas de maneira própria por cada organização. Em primeiro lugar, a natureza da atividade de cada organização determina a maior ou menor importância do ambiente técnico ou do ambiente institucional na formulação das estratégias de ação. Segundo, os esquemas interpretativos dos membros da organização, em especial daqueles que detêm o seu domínio, influenciam decisivamente na escolha do nível do contexto ambiental a ser prioritariamente considerado para análise: local, regional, nacional e internacional. Cada organização se orienta "pelo contexto institucional no nível que mais se coaduna com a sua trajetória e, portanto, com sua lógica interior" (Machado-da-Silva e Fernandes, 1998, p. 49).

Tal circunstância chama a atenção para o papel dos membros organizacionais no processo de interpretação e construção social da realidade. Nessa direção, a vertente cognitiva da análise da mudança e da estabilidade nas organizações enfatiza a importância dos esquemas interpretativos na captação de valores contextuais e na atribuição de significados, que tendem a ser difundidos no interior da organização e a ser relacionados à sua estrutura e ao seu posicionamento estratégico (Ranson, Hinings e Greenwood, 1980).

Esquemas interpretativos fundam-se sobre valores/crenças e constituem bases compartilhadas sobre as causas dos eventos e sobre a forma de agir em cada situação. Eles propiciam significado ao mundo organizacional ao mesmo tempo que possuem caráter articulador das orientações estratégicas da organização, atuando como referência para os propósitos organizacionais, os princípios de organização e os critérios de avaliação de desempenho (Hinings e Greenwood, 1988). Conforme a definição de Machado-da-Silva e Fonseca (1993, p. 150), os esquemas interpretativos são "pressupostos resultantes da elaboração e arquivamento mental da percepção de objetos dispostos na realidade, que operam como quadros de referência, compartilhados e freqüentemente implícitos, de eventos e comportamentos apresentados pelos agentes organizacionais em diversas situações". 
Sugere-se, portanto, que "um ímpeto ambiental é, provavelmente, necessário para a mudança começar, mas a maneira como o ambiente afeta a mudança depende dos atuais esquemas interpretativos e da estrutura organizacional" (Bartunek, 1984, p. 356). As pressões contextuais preconizam e potencializam mudanças estruturais; porém estas só serão efetivamente realizadas se no processo de interação social aqueles que detêm o domínio da organização absorverem e incorporarem os seus significados, ao longo do tempo (Ranson, Hinings e Greenwood, 1980).

Nessa linha de raciocínio, valores ambientais e organizacionais apresentam-se intimamente relacionados. A presença de uma representação cognitiva pode abrir caminho para a institucionalização de parâmetros e de atividades que antes pareciam impensáveis (Zucker, 1983). Dessa forma, a influência de valores ambientais sobre o direcionamento da organização é mediada pela forma de apreensão desses valores pela estrutura de conhecimento da organização, via interpretação dos seus dirigentes. Reitera-se, portanto, a importância do conceito de contexto institucional de referência, ou seja, da representação do nível de análise ambiental (local, regional, nacional ou internacional), envolvendo tanto características do ambiente técnico quanto do institucional, que a organização adota como guia para suas ações e estratégias (Machado-da-Silva, Fonseca e Fernandes, 1999a).

O contexto institucional de referência varia entre as organizações, mesmo entre aquelas integrantes do mesmo segmento populacional. Também é possível que ocorra inconsistência entre o contexto efetivo de competição de uma organização (aquele que objetivamente orienta as relações de troca das organizações de determinado setor) e o que ela adota como sendo o seu contexto institucional de referência. Tal possibilidade implica afirmar que uma organização que absorva os valores de um determinado nível ambiental, não só os utilizará como referência para suas estratégias de ação como terá dificuldades em visualizar e adotar práticas institucionalizadas em um contexto mais amplo, caso elas não se coadunem com os valores vigentes no seu sistema de interpretação (Machadoda-Silva, Fonseca e Fernandes, 2000). As estratégias de ação das organizações são coerentes com "as crenças e valores externamente aceitos e compartilhados, interpretados de acordo com o quadro de referência cultural e relacional da organização" (Machado-da-Silva e Fonseca, 1996, p. 110).

Subjacente ao raciocínio até aqui desenvolvido estão presentes aspectos culturais ligados à noção de valores compartilhados. Valores são preferências por determinados objetivos e cursos de ação, de modo que afetam a escolha do grupo em favor de uma entre várias alternativas possíveis (Beyer, 1981; Enz, 1988). O uso do conceito de valores permite que se reconheça a multiplicidade de preferências no concernente a meios e fins, podendo-se enfatizar as diferentes posi- 
ções de valor e sua relação com as ações, as regras e a estrutura organizacional. Além disso, o enfoque nos valores reflete a questão da legitimidade de ações, regras e estruturas que se considera adequadas à medida que são compartilhadas pelos dirigentes e outros membros da organização, mediante mecanismos de adesão e/ou imposição.

Em resumo, os fundamentos da teoria institucional chamam a atenção para as pressões por legitimidade e aceitação social, de modo que esses padrões fornecem elementos para a constituição dos critérios para a orientação organizacional, em adição àqueles com ênfase na relação econômica de custo-benefício. $\mathrm{O}$ ambiente penetra na organização, influenciando a criação de lentes para a leitura do mundo e para o delineamento de suas ações e estruturas. Contudo, o componente associado à interpretação e à constituição de quadros de referência próprios de cada organização torna essas pressões ambientais sujeitas à escolhas coerentes com a amplitude de valorização do contexto institucional pela organização. Constata-se, assim, a presença de níveis de análise ambiental na esfera de atuação das organizações sob o mesmo conjunto de pressões contextuais, aos quais são creditados diferentes graus de importância, de acordo com a visão de mundo decorrente da estrutura de valores consolidada internamente.

Nesse sentido, estabelece-se um eixo relacionando valores ambientais, esquemas de interpretação e valores organizacionais que atuam de forma a constituir uma rede de conexões causais sobre a qual se funda a compreensão da aprendizagem organizacional. Tradicionalmente concebida sob a ótica contingencial, com base em características estruturais, a aprendizagem organizacional passa a ser agregada à dimensão cultural que a torna dependente não só da interação simbólica interna à organização, mas também do grau de participação de valores ambientais institucionalizados, presentes no sistema interpretativo do grupo de dirigentes. Na Figura 1 procura-se representar esse sistema de relações.

É importante notar a presença do conceito de arquétipo que perpassa a construção teórica proposta, complementando e fortalecendo o modelo integrado de aprendizagem organizacional. A análise de estruturas e sistemas organizacionais deve ser compreendida de forma articulada, de acordo com uma visão holística. Deve-se reconhecer a interação mutuamente constitutiva entre valores, estruturas e sistemas da organização (Greenwood e Hinings, 1993; Cooper et al., 1996).

A estrutura constitui uma representação de valores e interesses organizacionais e institucionais, não se sujeitando exclusivamente a delineamento racional. Nesse sentido, define-se arquétipo como "uma composição de estruturas e sistemas que ganham coerência ou orientação a partir de um conjunto de idéias, crenças e valores" (Hinings e Greenwood, 1988, p. 4). Como tal, incorpora de modo consistente um único esquema interpretativo. Para melhor compreensão do con- 
ceito de arquétipo, considera-se que: (1) é institucionalmente definido; (2) é identificado nas organizações a partir de formas estruturais; (3) não representa, necessariamente, o comprometimento de todos os membros da organização com seus valores subjacentes (Greenwood e Hinings, 1993).

\section{Figura 1: Modelo Integrado de Aprendizagem Organizacional}

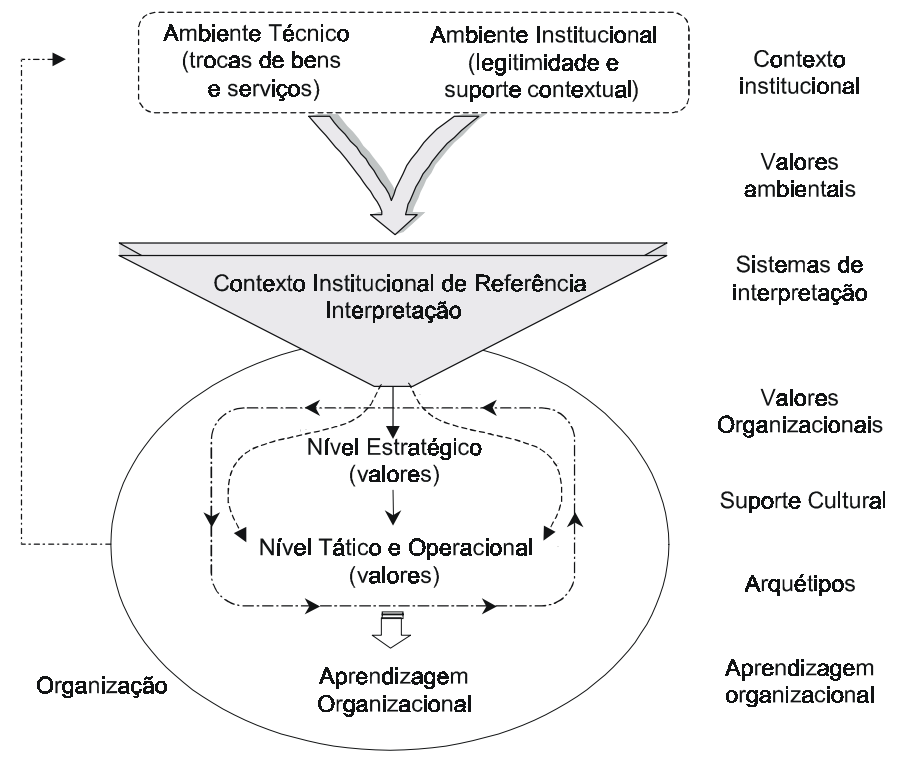

Em face do exposto, torna-se factível considerar que a aprendizagem organizacional só se realiza efetivamente na constatação da importância de um arranjo estrutural atrelado a valores específicos (delineando um arquétipo para a aprendizagem), com tendência de elevado comprometimento ou alto grau de congruência entre valores dos membros da organização em relação aos valores do arquétipo. Assim, pode-se considerar duas hipóteses: (1) organizações com contexto institucional de referência coincidente com o contexto ambiental efetivo apresentam maior predisposição para a aprendizagem organizacional; (2) organizações com contexto institucional de referência mais restrito que o contexto ambiental efetivo apresentam menor predisposição para a aprendizagem organizacional.

O design organizacional, de acordo com as características do arquétipo de aprendizagem, tende a variar segundo o nível do contexto em que se visualiza os valores ambientais. À medida que ocorra maior congruência entre valores ambientais e organizacionais, em proporção tal que envolva o conjunto de valores subjacentes ao arquétipo, aumenta a probabilidade de conformidade da organiza- 
ção com os atributos da aprendizagem organizacional. Tal assertiva se justifica pela premissa que os valores dispostos no contexto ambiental efetivo e os valores da aprendizagem organizacional estão situados em um mesmo nível de contexto institucional. Dessa forma, a predição é a de que o nível maior de amplitude do contexto institucional de referência da organização propende a engendrar maior predisposição para a conformidade com o arquétipo de aprendizagem organizacional; o inverso seria igualmente verdadeiro.

Assim, o constructo aprendizagem organizacional passa a ser concebido em uma perspectiva integradora que envolve elementos cognitivos, institucionais e culturais. Estes elementos são instrumentalizados na constituição de um arquétipo para a aprendizagem. Decorre dessa arquitetura a existência de processos de construção e reconstrução ao longo de três momentos: na relação entre valores ambientais e organizacionais, na própria interação dos valores organizacionais e na mútua constituição entre estruturas e significados, marcando o relacionamento entre o domínio institucional e o domínio da ação.

\section{A Situação em Estudo}

Em face do problema de pesquisa endereçado neste artigo, que se refere à influência de valores ambientais e organizacionais sobre a aprendizagem organizacional em empresas do setor de alimentos no Estado do Paraná, utilizou-se um delineamento do tipo levantamento. Tal opção demonstrou-se adequada, à medida que se procurou verificar as relações entre as variáveis que podem afetar o constructo aprendizagem organizacional.

Para a consecução desse objetivo, as empresas objeto do estudo foram agrupadas em diferentes clusters, com base na identificação de seu contexto institucional de referência. Desse modo foi possível avaliar diferenças relativamente à predisposição para a aprendizagem organizacional entre os grupos, por meio da utilização de procedimentos estatísticos de análise multivariada de variância. A perspectiva de análise é transversal e 1999 é o ano de referência da presente investigação.

Definiu-se como população da pesquisa as empresas produtoras de alimentos, com 100 ou mais empregados, localizadas no Estado do Paraná. O critério principal para a escolha desse setor foi a constatação de que as empresas industriais desse segmento vêm enfrentando pressões ambientais crescentes com a abertura do mercado e a estabilização da economia. A exclusão de micro e pequenas empresas da população considerada decorreu do uso do critério de complexida- 
de; organizações desse porte usualmente possuem estruturas mais simples. O procedimento de amostragem foi por adesão, obtendo-se 42 organizações respondentes, que corresponde a $34,7 \%$ das 121 empresas componentes do universo sob investigação.

Os dados primários foram coletados por meio de questionário enviado via correio para três dirigentes do nível estratégico de cada uma das organizações integrantes da população. As perguntas do questionário foram divididas em blocos que se destinaram, respectivamente, à caracterização do respondente ( 8 questões), à definição do contexto institucional de referência da organização (13 questões de múltipla escolha) e à avaliação da estrutura e valores do arquétipo de aprendizagem (62 questões elaboradas em escala do tipo Likert, de 7 pontos). A operacionalização da coleta e tratamento dos dados ocorreu em três etapas, conforme se demonstra no Quadro 1.

\section{Quadro 1: Etapas da Pesquisa}

\begin{tabular}{l|l|l}
\hline \multirow{2}{*}{ Etapa } & \multicolumn{2}{c}{ Variáveis da Pesquisa } \\
\cline { 2 - 3 } & \multicolumn{1}{c|}{ Valores } & \multicolumn{1}{c}{ Aprendizagem Organizacional } \\
\hline $\begin{array}{l}\mathbf{1}^{\text {a }} \text { Etapa: Análise dos dados } \\
\text { secundários e preparação do } \\
\text { instrumento de coleta de dados }\end{array}$ & Levantamento dos valores ambientais & $\begin{array}{l}\text { ・ Definição do arquétipo de } \\
\text { aprendizagem }\end{array}$ \\
\hline $\begin{array}{l}\mathbf{2}^{\mathbf{a}} \text { Etapa: Coleta de dados nas } \\
\text { empresas (Questionário) }\end{array}$ & $\begin{array}{l}\text { • Avaliação da convergência entre os } \\
\text { valores organizacionais e do } \\
\text { contexto institucional } \\
\text { Identificação do contexto } \\
\text { institucional de referência das } \\
\text { empresas }\end{array}$ & $\begin{array}{l}\text { Verificação das características } \\
\text { estruturais e valores associados ao } \\
\text { arquétipo de aprendizagem }\end{array}$ \\
\hline $\begin{array}{l}\mathbf{3}^{\mathbf{a}} \text { Etapa: Análise quantitativa dos } \\
\text { dados primários }\end{array}$ & $\begin{array}{l}\text { Avaliação da influência dos valores ambientais e organizacionais sobre a } \\
\text { predisposição para a aprendizagem organizacional }\end{array}$ \\
\hline
\end{tabular}

Em decorrência da lógica institucional do referencial teórico deste estudo, tornou-se necessário, em primeiro lugar, realizar a análise da situação do setor de alimentos no conjunto dos valores ambientais em que está inserido. Para tanto, realizou-se trabalho de levantamento e análise de fontes secundárias sobre o contexto ambiental, que resultou em caracterização, o quanto possível fiel, dos parâmetros delineadores dos ambientes técnico e institucional. A técnica de triangulação dos dados foi exaustivamente utilizada nessa fase. Dessa forma, identificou-se o conjunto dos valores subjacentes a três níveis de análise ambiental: internacional, nacional e regional.

A definição desses parâmetros também subsidiou a construção do questionário, única fonte primária de coleta de dados. Os valores ambientais foram apre- 
sentados na forma de perguntas fechadas de diferentes tipos aos dirigentes, visando a identificação do contexto institucional de referência das organizações objeto do estudo.

Em segundo lugar, definiu-se a priori as características que permitiram consolidar o delineamento de um arquétipo de aprendizagem. Assim, na análise dos dados secundários descreve-se os elementos de ordem estrutural, bem como os valores subjacentes que, de modo consistente, definem o desenho de um arquétipo de aprendizagem, construído com base na literatura especializada ${ }^{(1)}$ sobre o tema. A partir da definição desses elementos foi possível elaborar questões para integrar o questionário, a fim de identificar a predisposição para a aprendizagem das empresas participantes da pesquisa, mediante a avaliação do grau de presença das características do arquétipo.

Na seqüência deste artigo apresenta-se as seções de análise de acordo com a lógica temporal adotada para a coleta dos dados secundários e primários. Essas seções são as seguintes: (1) análise do contexto institucional; (2) análise do arquétipo de aprendizagem; e (3) análise das relações entre as variáveis. Cabe assinalar que o limite de espaço permitido para artigos em revista científica obrigou os autores deste trabalho a reduzir substancialmente o texto de análise dos dados, o que se realizou a contragosto diante da extensão do material coletado e das possibilidades analíticas. Procurou-se minimizar essa limitação mediante a elaboração de quadros o quanto possível auto-explicativos.

\section{Análise do Contexto Institucional}

A indústria de alimentos nacional desenvolveu-se, nos últimos anos, em um contexto marcado principalmente pela abertura e pela estabilização da economia brasileira. A necessidade de modernização se fez presente na década de 90 , embora o setor, entre 1968 e 1998, tenha crescido em média 4\% ao ano, favorecido pelo aumento da população, do nível de renda e do grau de urbanização.

O processo de abertura para o mercado internacional e a necessidade de adaptação aos novos padrões de qualidade e produtividade aumentaram a preocupação com os ganhos em eficiência e melhoria do nível de competitividade, reforçando a criação de programas de reestruturação das empresas produtoras de alimentos (ABIA, 1999). Assim, "a desregulamentação, abertura comercial e formação do Mercosul [...] ensejaram alterações no ambiente competitivo, que intensificaram a concorrência, de um lado, e abriram um leque de novas oportunidades de negócio, de outro" (Farina, Azevedo e Saes, 1997, p. 230).

A partir dessas breves considerações, apresenta-se no Quadro 2 a caracterização resumida dos indicadores setoriais relevantes da dimensão técnica do ambi- 
ente, elaborada com base nas dimensões de incerteza e dependência do esquema de análise proposto por Scott (1992). Diversas fontes secundárias de dados (documentos, revistas especializadas, jornais relevantes e outras) foram utilizadas para garantir maior confiabilidade e validade à sintese contida no quadro.

\section{Quadro 2: Dimensões do Ambiente Técnico: Incerteza e Dependência}

\begin{tabular}{|c|c|}
\hline Dimensões & Indicadores Setoriais \\
\hline $\begin{array}{l}\text { Aspectos de incerteza } \\
\text { - homogeneidade/heterogeneidade } \\
\text { similaridade dos elementos } \\
\text { ambientais }\end{array}$ & $\begin{array}{l}\text { - Consumo: constata-se a tendência rumo a padrões internacionais de consumo, } \\
\text { embora a diferenciação por nível de renda ainda seja fator relevante. } \\
\text { Fornecedores: em face da sua natureza agropecuária, não parece ter ocorrido } \\
\text { alterações recentes, permanecendo o relacionamento com vários fornecedores } \\
\text { de matéria-prima (Ferraz, Kupfer e Haguenauer, 1997). }\end{array}$ \\
\hline $\begin{array}{l}\text { - estabilidade/variabilidade } \\
\text { taxa de mudança dos elementos } \\
\text { ambientais }\end{array}$ & $\begin{array}{l}\text { - Setor tido como possuidor de maturidade tecnológica, com a tecnologia } \\
\text { produtiva, em geral, comum e disponível, indicando relativa estabilidade do } \\
\text { progresso tecnológico (Wilkinson, 1995; Martinelli, 1997). }\end{array}$ \\
\hline $\begin{array}{l}\text { - ameaça/s egurança } \\
\text { vulnerabilidade da organização ao } \\
\text { seu ambiente }\end{array}$ & $\begin{array}{l}\text { - Tradicionalmente, o setor sofre pouco com as ameaças externas e flutuações } \\
\text { cíclicas da economia. Seu desempenho tem como fatores de estabilidade a } \\
\text { relação direta com o aumento da população, da renda e da urbanização, além } \\
\text { de ser produtor de bens essenciais (Viglio, 1996; ABIA, 1999). }\end{array}$ \\
\hline $\begin{array}{l}\text { - interconexão/isolamento } \\
\text { extensão na qual a organização está } \\
\text { ligada às outras }\end{array}$ & $\begin{array}{l}\text { - Forte conexão com consumidores que, em geral, têm poder de barganha } \\
\text { reduzido por se tratar de bens essenciais. Forte ligação com fornecedores dada } \\
\text { a dependência de recursos agrícolas perecíveis, requerendo contínuo fluxo de } \\
\text { abastecimento, sem a formação de estoques. Por fim, novas exigências de } \\
\text { qualidade, diversificação e competitividade pressionam para maior troca de } \\
\text { informações e integração dos elos da produção (Belik, 1995; Carmo, 1996; } \\
\text { Ferraz, Kupfer e Haguenauer, 1997; Vieira, 1997). }\end{array}$ \\
\hline $\begin{array}{l}\text { - coordenação/não-coordenação } \\
\text { extensão na qual o ambiente é } \\
\text { organizado ou estruturado }\end{array}$ & $\begin{array}{l}\text { - Com fornecedores há ascensão de parcerias para a garantia de preço e } \\
\text { qualidade; com distribuidores há intensificação do relacionamento com vistas ao } \\
\text { monitoramento do consumo. Além disso, constata-se tendência forte de } \\
\text { concentração do setor via fusões e aquisições. }\end{array}$ \\
\hline $\begin{array}{l}\text { Aspectos de dependência } \\
\text { - abundância/escassez } \\
\text { disponibilidade de recursos no } \\
\text { ambiente }\end{array}$ & $\begin{array}{l}\text { - Recursos humanos e insumos não parecem oferecer restrições às necessidades } \\
\text { do setor. Recursos financeiros estão disponíveis, mas as condições de crédito } \\
\text { são fatores relevantes. }\end{array}$ \\
\hline $\begin{array}{l}\text { - concentração/dispersão } \\
\text { distribuição de recursos no } \\
\text { ambiente }\end{array}$ & $\begin{array}{l}\text { - Desconsiderando os custos de aquisição, como tarifas de importação e custos } \\
\text { financeiros, os recursos necessários para o setor são conhecidos e estão } \\
\text { disponíveis no mercado. }\end{array}$ \\
\hline
\end{tabular}

Fonte: dados secundários da pesquisa.

No que concerne à dimensão institucional do ambiente procurou-se identificar valores institucionalizados na sociedade com possibilidades de pressionar as estruturas, as diretrizes e as estratégias de ação das empresas em estudo no sentido de adequação aos conceitos socialmente estabelecidos. Assim, com base na assertiva de que a visualização do contexto institucional varia entre as organizações, foi possível distinguir valores predominantes para a indústria de alimentos 
em três níveis ambientais: regional, nacional e internacional. Para se chegar a esse conjunto de valores, adotou-se os procedimentos que se seguem.

Em primeiro lugar, realizou-se levantamento de fatores de influência sobre a estrutura e o desempenho da indústria de transformação, mencionados de forma consistente em periódicos acadêmicos e do grande público. A seguir, classificouse essa relação de fatores de acordo com a menção do nível de análise ambiental predominante: internacional, nacional ou regional. Posteriormente, tais fatores foram divididos em blocos segundo a sua similaridade temática.

Entende-se que as fontes selecionadas são formadoras de opinião pública e/ou difusoras da visão acadêmica, fornecendo, portanto, um quadro representativo dos temas e problemas nacionais e internacionais mais relevantes para o setor industrial. As fontes consultadas foram: Conjuntura Econômica, Revista de Administração de Empresas (RAE), Informações FIPE, Análise Conjuntural IPARDES/PR e o jornal Folha de São Paulo. A diversidade do universo de análise objetivou abranger as várias possibilidades de linhas de pensamento em relação à situação econômica e empresarial do país. Vale ressaltar que o levantamento dos fatores, mediante análise documental e de conteúdo, resultou em um quadro conciso e com alto grau de concordância no que tange às diversas fontes utilizadas.

Adotou-se como critério para a consideração dos artigos o fato de enfocarem mudanças em curso ou tidas como necessárias de serem levadas em conta no delineamento das estratégias, pelo sistema de gestão e pela estrutura das organizações industriais, de modo geral, e do setor alimentício, em particular. A situação e as transformações ambientais de ordem internacional, nacional e regional deveriam estar mencionadas nas publicações, explícita ou implicitamente, no período entre janeiro de 1993 e dezembro de 1998. Justifica-se tal critério a partir do pressuposto da vertente cognitiva da teoria institucional sobre a influência de conceitos, normas e práticas socialmente aceitas, presentes no contexto institucional, nas diretrizes de ação e de formulação das estratégias em organizações. Além disso, entende-se que o dinamismo ambiental constitui fator importante para a mudança organizacional, uma vez que se relaciona à percepção de que transformações e ajustes organizacionais são necessários para a sobrevivência continuada da empresa.

Com a base proporcionada por essa primeira classificação de fatores de influência, partiu-se para a segunda etapa da investigação com o objetivo de verificar o significado e a correspondência desses fatores no campo específico da indústria de alimentos no Brasil. Para traçar esse paralelo utilizou-se dados fornecidos pela Associação Brasileira da Indústria da Alimentação (ABIA), bem como artigos, estudos e relatórios de instituições financeiras com enfoque exclusivo no setor alimentício. 
A última etapa para a caracterização do contexto institucional do setor consistiu na análise do conjunto de informações coletadas, visando a efetuar associações entre os fatores de influência, dispostos por nível de análise ambiental, de modo a permitir identificar os valores subjacentes, representativos da lógica de ação adotada pelas empresas produtoras de alimentos. No Quadro 3 sintetiza-se as diferenças básicas entre os três níveis de análise ambiental.

\section{Quadro 3: Características Contextuais por Nível de Análise Ambiental}

\begin{tabular}{|c|c|c|c|}
\hline & Internacional & Nacional & Regional \\
\hline $\begin{array}{l}\text { Objetivo/ } \\
\text { Perspectiva }\end{array}$ & $\begin{array}{l}\text { - Competitividade } \\
\text { internacional } \\
\text { - Global }\end{array}$ & $\begin{array}{l}\text { - Concorrência interna } \\
\text { - Nacional }\end{array}$ & $\begin{array}{l}\text { - Espaço no mercado } \\
\text { - Regional }\end{array}$ \\
\hline $\begin{array}{l}\text { Mercado } \\
\text { consumidor }\end{array}$ & $\begin{array}{l}\text { - Padrões de consumo } \\
\text { internacional }\end{array}$ & $\begin{array}{l}\text { - Adaptação às novas faixas } \\
\text { de renda }\end{array}$ & - Consumo regional \\
\hline Lógica de ação & $\begin{array}{l}\text { - Proatividade/Dinamismo } \\
\text { - Inovação/Modernização }\end{array}$ & $\begin{array}{l}\text { - Reação/Adaptação } \\
\text { - Imitação/Reestruturação }\end{array}$ & $\begin{array}{l}\text { - Reação/Adaptação } \\
\text { - Imitação/Reestruturação }\end{array}$ \\
\hline $\begin{array}{l}\text { Fator } \\
\text { determinante }\end{array}$ & - Qualidade & - Custo & - Custo \\
\hline Estratégia & $\begin{array}{l}\text { - Diferenciação (hábitos, } \\
\text { agregação) } \\
\text { - Concentração (estratégia } \\
\text { global) e coordenação } \\
\text { - Monitoração ampla } \\
\text { - Expansão internacional }\end{array}$ & $\begin{array}{l}\text { - Diferenciação (faixas de } \\
\text { renda) } \\
\text { - Concentração (ganhos de } \\
\text { escala, proteção) } \\
\text { - Monitoração limitada } \\
\text { nacionalmente } \\
\text { - Consolidação ou espansão } \\
\text { nacional }\end{array}$ & $\begin{array}{l}\text { - Diferenciação (faixas de } \\
\text { renda) } \\
\text { - Concentração (ganhos de } \\
\text { escala, proteção) } \\
\text { - Monitoração limitada } \\
\text { regionalmente } \\
\text { - Consolidação ou espansão } \\
\text { regional }\end{array}$ \\
\hline $\begin{array}{l}\text { Bases da } \\
\text { competitividade }\end{array}$ & $\begin{array}{l}\text { - Flexibilidade } \\
\text { - Integração da cadeia } \\
\text { produtiva } \\
\text { - Inovação }\end{array}$ & $\begin{array}{l}\text { - Controle de custos } \\
\text { - Aquisição de tecnologia } \\
\text { - Apoio do Governo Federal }\end{array}$ & $\begin{array}{l}\text { - Controle de custos } \\
\text { - Aquisição de tecnologia } \\
\text { - Apoio do Governo (PR) }\end{array}$ \\
\hline Tecnologia & - Desenvolvimento/Parcerias & - Aquisição de tecnologia & - Aquisição de tecnologia \\
\hline Ecologia & - Consciência ecológica & - Preocupação incipiente & - Preocupação incipiente \\
\hline Qualidade & $\begin{array}{l}\text { - Qualidade (requisito } \\
\text { essencial) }\end{array}$ & $\begin{array}{l}\text { - Qualidade (diferencial } \\
\text { competitivo) }\end{array}$ & $\begin{array}{l}\text { - Qualidade (requisito do } \\
\text { consumo) }\end{array}$ \\
\hline Papel do Estado & $\begin{array}{l}\text { - Promoção do comércio } \\
\text { exterior } \\
\text { - Controle das práticas } \\
\text { comerciais }\end{array}$ & $\begin{array}{l}\text { - Controle da concorrência } \\
\text { interna } \\
\text { - Redução de entraves à } \\
\text { competitividade interna }\end{array}$ & $\begin{array}{l}\text { - Fomento da indústria e } \\
\text { infra-estrutura } \\
\text { - Redução de entraves à } \\
\text { competittividade regional }\end{array}$ \\
\hline
\end{tabular}

Fonte: dados secundários da pesquisa.

As características constantes do Quadro 3, que definem três níveis de contexto institucional, forneceram a base da elaboração de um dos blocos de perguntas do questionário submetido aos dirigentes do nível estratégico das empresas investi- 
gadas. As respostas ao questionário possibilitaram identificar o contexto institucional de referência de cada uma dessas empresas. Assim, foi possível agrupálas de acordo com o nível de análise do ambiente que adotam como referência.

Neste ponto de desenvolvimento do presente artigo, cabe importante observação: para a continuidade da análise neste estudo considerou-se o contexto institucional internacional como o contexto ambiental efetivo do setor produtor de bens alimentícios. As principais razões que justificam essa opção são as seguintes: (1) a crescente influência dos fatores associados ao contexto internacional sobre as indústrias no país; (2) a acentuação da influência desses fatores vem compondo os contornos de definição do ambiente competitivo de grande parte das indústrias de alimentos, principalmente daquelas que se enquadram no perfil da população da presente pesquisa; (3) a predominância, na literatura especializada, de uma caracterização do setor de acordo com os fatores do contexto internacional; (4) a maior amplitude de análise das condições ambientais proporcionadas pela visão do contexto internacional, o qual parece ser mais coerente com o momento atual de expansão dos níveis de comércio global e de internacionalização de empresas.

\section{Análise do Arquétipo de Aprendizagem Organizacional}

A construção do arquétipo de aprendizagem organizacional objetivou definir parâmetros de ordem estrutural e cultural que possibilitassem classificar as empresas pesquisadas em termos de grau de aderência ao arquétipo. Assim, quanto maior o grau de aderência às características do arquétipo, maior a predisposição das empresas para a aprendizagem organizacional. Os parâmetros estruturais e de sistemas considerados para a construção do arquétipo permitiram um desenho consistente e coerente com o conjunto de valores subjacente, conforme se pode observar nos Quadros 4 e 5, apresentados na seqüência.

A escolha das obras acadêmicas (artigos, livros, capítulos de livros) para a construção do arquétipo de aprendizagem deu-se com base na presença de pelo menos uma das características seguintes: (1) no mínimo uma seção do trabalho tratou da aplicabilidade prática dos conceitos abordados; (2) forte componente prescritivo no desenvolvimento do texto; (3) revisão da literatura sobre o tema que se enquadrasse ao menos em um dos dois critérios anteriores.

As características selecionadas para compor o arquétipo deveriam estar presentes, necessariamente, na maior parte dos textos escolhidos. O cumprimento de tal exigência foi relativamente fácil, tendo em vista a alta concordância sobre as características de uma organização com capacidade para aprender nas obras consultadas, independentemente da perspectiva teórica dos autores. 
É comum, ao se tratar de organizações que aprendem, observar a presença de características que se relacionam a um conjunto subjacente de valores de aprendizagem. Conforme afirma Dodgson (1993), a aprendizagem das empresas é maior do que a soma da aprendizagem individual de seus empregados. Nesse sentido, o autor constata grande concordância entre diversos estudiosos quanto ao papel das normas e valores compartilhados na explicação da aprendizagem organizacional. O conjunto de valores resultante da presente análise da literatura especializada sobre o tema, que consta do Quadro 4, reflete esse posicionamento.

\section{Quadro 4: Arquétipo de Aprendizagem - Descrição dos Valores}

\begin{tabular}{|c|c|}
\hline Valores & Descrição \\
\hline $\begin{array}{c}\text { Grupo } 1 \text { - Inovação e } \\
\text { mudança }\end{array}$ & $\begin{array}{l}\text { - experimentação e aceitação do risco; autonomia e abertura a erros; } \\
\text { desprendimento da tradição; criatividade e inovação; abertura a novas idéias e } \\
\text { mudança; auto-questionamento e reflexão }\end{array}$ \\
\hline Grupo 2 - Proatividade & $\begin{array}{l}\text { - monitoração do ambiente; variedade de requisito; proatividade e dinamismo; } \\
\text { caos criativo; auto-regulação e auto-organização; intenção }\end{array}$ \\
\hline Grupo 3 - Pluralismo & $\begin{array}{l}\text { - conflitos construtivos; abertura à múltiplos pontos de vista; democratização da } \\
\text { geração de conhecimentos }\end{array}$ \\
\hline $\begin{aligned} \text { Grupo } 4 \text { - Compartilhamento } & \text { e lições passadas }\end{aligned}$ & $\begin{array}{l}\text { - compartilhamento de idéias; incentivar a memória organizacional; resgatar lições } \\
\text { passadas; socialização e comunicação intensa; difusão e ampliação do } \\
\text { conhecimento }\end{array}$ \\
\hline Grupo 5 - Flexibilidade & $\begin{array}{l}\text { - mínima especificação crítica; redundância; especialização/generalização; } \\
\text { ambigüidade }\end{array}$ \\
\hline Grupo 6 - Capacitação & - ênfase na educação contínua; valorização de múltiplas habilidades \\
\hline $\begin{array}{c}\text { Grupo } 7-\text { Perspectiva } \\
\text { sistêmica }\end{array}$ & - mútua causalidade; visão holística \\
\hline
\end{tabular}

Fonte: literatura especializada sobre aprendizagem organizacional (vide Nota 1).

A descrição desse conjunto de valores remete às características estruturais e de sistemas que devem ser contempladas na construção de um arquétipo de aprendizagem, conforme se demonstra no Quadro 5. Em conseqüência, o delineamento dos sistemas organizacionais deve considerar os seguintes componentes: planejamento e tomada de decisão; recursos humanos; informação; comunicação; e inovação. Nessa mesma linha arquitetural, as seguintes dimensões estruturais precisam ser levadas em conta: diferenciação horizontal e vertical; formalização; e centralização. 


\section{Quadro 5: Arquétipo de Aprendizagem - Características de Estruturas e Sistemas}

\begin{tabular}{|c|c|}
\hline Sistemas e Estrutura & Características \\
\hline \multicolumn{2}{|l|}{ Sistemas } \\
\hline • Planejamento e Decisão & $\begin{array}{l}\text { - Proativo; pluralista; liderança altamente envolvida; orientação para o longo prazo; alta } \\
\text { disposição ao risco; intuitiva e analítica; planejamento flexível, interativo, não linear, } \\
\text { probabilístico; construção permanente }\end{array}$ \\
\hline - Recursos Humanos & $\begin{array}{l}\text { - Remuneração por habilidades e iniciativa; controle grupal; capacitação multifuncional; } \\
\text { elevada autonomia }\end{array}$ \\
\hline • Informações & $\begin{array}{l}\text { - Coleta sistemática; ampla difusão/acessabilidade; alto/sistemático contato com clientes } \\
\text { e fornecedores; fontes externa, interna, atemporal }\end{array}$ \\
\hline • Comunicação & - Ampla; formal e informal; alto grau de interação \\
\hline • Inovação & $\begin{array}{l}\text { - Elevada autonomia; alta criatividade; orientação proativa; baixo apego à tradição; erro } \\
\text { considerado legítimo e institucionalizado }\end{array}$ \\
\hline \multicolumn{2}{|l|}{ Estrutura } \\
\hline - Diferenciação & - Baixo grau de diferenciação; grupos de trabalho; flexível \\
\hline • Formalização & $\begin{array}{l}\text { - Baixo uso de regras e procedimentos, com orientação geral; baixa divisão de cargos } \\
\text { e papéis }\end{array}$ \\
\hline - Centralização & - Descentralizada; locus variável, grupo; relação de parceria, cooperação \\
\hline
\end{tabular}

Fonte: literatura especializada sobre aprendizagem organizacional (vide Nota 1).

As características de sistemas e estruturas que definem o arquétipo de aprendizagem, bem como a descrição dos valores subjacentes que constam dos Quadros 4 e 5, forneceram a base da elaboração de um dos blocos de perguntas do questionário submetido aos dirigentes do nível estratégico das empresas investigadas. As respostas ao questionário possibilitaram identificar o nível de predisposição para a aprendizagem organizacional dessas empresas, com base no grau de conformidade às características do arquétipo.

\section{Análise das Relações entre as Variáveis}

A análise precedente do contexto institucional e o delineamento do arquétipo de aprendizagem, além de possibilitar a definição de parâmetros para exame do setor de alimentos, também subsidiou a elaboração do questionário enviado aos dirigentes das empresas em estudo. A partir daqui, realiza-se a análise dos dados primários no sentido de verificar as hipóteses de pesquisa. O resultado da análise estatística dos dados coletados parece fornecer evidências seguras para a corroboração das duas hipóteses sob investigação, como se poderá observar na seqüência. 
Em primeiro lugar, foi possível verificar que diferentes níveis do contexto ambiental se configuram no sistema de interpretação das empresas, revelando maneiras distintas de considerar e captar as informações ambientais. Diferentes visões do ambiente estão em consonância com a lógica subjacente do conjunto dos valores organizacionais. Quatro grupos de empresas foram identificados, de acordo com o respectivo contexto institucional de referência, em conformidade com as características constantes do Quadro 3: internacional, nacional, regional, e um entre-tipos nacional/internacional.

Segundo, constatou-se tendência no sentido proposto pelas hipóteses de pesquisa: as variáveis relativas ao arquétipo apresentaram maiores escores à medida que se ampliou a visão do nível do contexto ambiental, como é possível observar na Tabela 1. Assim, as organizações com contexto institucional de referência internacional apresentaram escores maiores para as variáveis do arquétipo do que as de contexto institucional mais restrito. Além disso, verificou-se que o grupo de empresas com contexto institucional internacional apresenta valores convergentes com o contexto ambiental efetivo da indústria de alimentos. Já o grupo com contexto institucional de referência regional, com médias inferiores em quase todas as variáveis do arquétipo, exibe menor convergência com os valores do contexto ambiental efetivo.

Dessa forma, o nível de análise do contexto institucional revelou-se fundamental para explicar essas diferenças, já que permitiu definir, a partir dos esquemas interpretativos dos dirigentes de cada grupo de organizações, aqueles elementos do ambiente que foram considerados mais relevantes. Em conformidade com o referencial teórico do presente estudo, tais achados demonstram que os valores ambientais interferem na configuração estrutural e de valores das organizações, embora o tipo e a extensão da sua influência dependam da interpretação decorrente da visão de mundo própria dessas organizações.

As pressões impostas internacionalmente sobre o setor, definindo suas macrotendências, foram interpretadas de modo mais inclusivo somente por aquelas empresas que visualizam o contexto institucional de referência nesse nível. Toda a dinâmica de segmentação, de valorização nutricional e de aproximação entre os integrantes da cadeia produtiva alcançou maior plenitude na lógica de ação das organizações com contexto institucional de referência internacional. Já os demais grupos de empresas não possuem tal escopo de avaliação ambiental, restringindo os fatores que influenciam suas estratégias de ação. Esse achado vem corroborar a afirmação de Machado-da-Silva, Fonseca e Fernandes (1999b, p. 114) de que "as regras e os significados compartilhados no interior do contexto institucional da organização podem servir como buffers que dificultam a assimi- 
lação de práticas emergentes em um contexto mais amplo, caso tais práticas não se coadunem com os valores vigentes".

\section{Tabela 1: Descrição das Variáveis do Arquétipo segundo o Contexto Institucional de Referência das Empresas}

\begin{tabular}{|c|c|c|c|c|c|c|c|c|}
\hline Manova: Wilks, $p=0,048^{a} ; p=0,125^{b}$ & & $\begin{array}{c}\text { Amostra } \\
(n=42)\end{array}$ & $\begin{array}{c}\text { Internacional } \\
(n=2)\end{array}$ & $\begin{array}{c}\text { Nac/Inter } \\
(n=12)\end{array}$ & $\begin{array}{c}\text { Nacional } \\
(n=25)\end{array}$ & $\begin{array}{c}\text { Regional } \\
\quad(n=3)\end{array}$ & $\begin{array}{c}\text { Univariate } F- \\
\text { tests }^{a}\end{array}$ & $\begin{array}{l}\text { Univariate } F- \\
\text { tests }^{b}\end{array}$ \\
\hline Centralização & $\begin{array}{l}\text { média } \\
\mathrm{dp}\end{array}$ & $\begin{array}{l}4,35 \\
1,20\end{array}$ & $\begin{array}{l}4,94 \\
1,50\end{array}$ & $\begin{array}{l}4,79 \\
0,80\end{array}$ & $\begin{array}{l}4,36 \\
1,06\end{array}$ & $\begin{array}{l}2,08 \\
1,46\end{array}$ & $\begin{array}{l}F=6,06 \\
p=0,007\end{array}$ & $\begin{array}{l}F=5,71 \\
p=0,002\end{array}$ \\
\hline Comunicação & $\begin{array}{l}\text { média } \\
\mathrm{dp}\end{array}$ & $\begin{array}{l}3,79 \\
1,15\end{array}$ & $\begin{array}{l}4,83 \\
0,24\end{array}$ & $\begin{array}{l}4,09 \\
0,96\end{array}$ & $\begin{array}{l}3,74 \\
1,08\end{array}$ & $\begin{array}{r}2,33 \\
1,76\end{array}$ & $\begin{array}{l}F=3,25 \\
p=0,054\end{array}$ & $\begin{array}{l}F=2,78 \\
p=0,054\end{array}$ \\
\hline Decisão & $\begin{array}{l}\text { média } \\
\mathrm{dp}\end{array}$ & $\begin{array}{l}4,81 \\
0,90\end{array}$ & $\begin{array}{l}5,18 \\
0,76\end{array}$ & $\begin{array}{l}5,13 \\
0,87\end{array}$ & $\begin{array}{l}4,80 \\
0,66\end{array}$ & $\begin{array}{l}3,43 \\
1,86\end{array}$ & $\begin{aligned} F & =4,19 \\
p & =0,026\end{aligned}$ & $\begin{aligned} F & =3,51 \\
p & =0,024\end{aligned}$ \\
\hline Diferenciação & $\begin{array}{l}\text { média } \\
\mathrm{dp}\end{array}$ & $\begin{array}{l}3,69 \\
1,21\end{array}$ & $\begin{array}{l}4,92 \\
0,59\end{array}$ & $\begin{array}{l}4,34 \\
1,25\end{array}$ & $\begin{array}{l}3,49 \\
0,99\end{array}$ & $\begin{array}{l}1,89 \\
0,51\end{array}$ & $\begin{array}{l}F=6,45 \\
p=0,005\end{array}$ & $\begin{array}{l}F=5,77 \\
p=0,002\end{array}$ \\
\hline Formalização & $\begin{array}{l}\text { média } \\
\mathrm{dp}\end{array}$ & $\begin{array}{l}3,61 \\
0,80\end{array}$ & $\begin{array}{l}2,94 \\
0,44\end{array}$ & $\begin{array}{l}3,84 \\
1,06\end{array}$ & $\begin{array}{l}3,58 \\
0,68\end{array}$ & $\begin{array}{l}3,33 \\
0,63\end{array}$ & $\begin{array}{l}F=0,97 \\
p=0,389\end{array}$ & $\begin{array}{l}F=0,91 \\
p=0,443\end{array}$ \\
\hline Informação & $\begin{array}{l}\text { média } \\
\mathrm{dp}\end{array}$ & $\begin{array}{l}4,18 \\
0,84\end{array}$ & $\begin{array}{l}4,83 \\
0,47\end{array}$ & $\begin{array}{l}4,61 \\
0,73\end{array}$ & $\begin{array}{l}4,09 \\
0,76\end{array}$ & $\begin{array}{l}2,78 \\
0,19\end{array}$ & $\begin{array}{l}F=5,82 \\
p=0,008\end{array}$ & $\begin{array}{l}F=5,87 \\
p=0,002\end{array}$ \\
\hline Inovação & $\begin{array}{l}\text { média } \\
\mathrm{dp}\end{array}$ & $\begin{array}{l}3,86 \\
0,71\end{array}$ & $\begin{array}{l}4,39 \\
0,05\end{array}$ & $\begin{array}{l}4,07 \\
0,77\end{array}$ & $\begin{array}{l}3,81 \\
0,65\end{array}$ & $\begin{array}{l}3,05 \\
0,70\end{array}$ & $\begin{array}{l}F=2,92 \\
p=0,071\end{array}$ & $\begin{array}{l}F=2,30 \\
p=0,093\end{array}$ \\
\hline Planejamento & $\begin{array}{l}\text { média } \\
\mathrm{dp}\end{array}$ & $\begin{array}{l}4,25 \\
1,20\end{array}$ & $\begin{array}{l}4,50 \\
2,12\end{array}$ & $\begin{array}{l}4,56 \\
0,94\end{array}$ & $\begin{array}{l}4,32 \\
1,15\end{array}$ & $\begin{array}{l}2,33 \\
0,58\end{array}$ & $\begin{array}{l}F=3,95 \\
p=0,031\end{array}$ & $\begin{array}{l}F=3,37 \\
p=0,028\end{array}$ \\
\hline Recursos Humanos & $\begin{array}{l}\text { média } \\
\mathrm{dp}\end{array}$ & $\begin{array}{l}3,81 \\
0,87\end{array}$ & $\begin{array}{l}4,10 \\
0,14\end{array}$ & $\begin{array}{l}4,19 \\
0,99\end{array}$ & $\begin{array}{l}3,77 \\
0,70\end{array}$ & $\begin{array}{l}2,47 \\
0,90\end{array}$ & $\begin{array}{l}F=5,06 \\
p=0,014\end{array}$ & $\begin{array}{l}F=3,87 \\
p=0,016\end{array}$ \\
\hline Flexibilidade da Estratégia & $\begin{array}{l}\text { média } \\
\mathrm{dp}\end{array}$ & $\begin{array}{l}3,81 \\
1,37\end{array}$ & $\begin{array}{l}2,75 \\
1,06\end{array}$ & $\begin{array}{l}3,31 \\
0,98\end{array}$ & $\begin{array}{l}4,07 \\
1,50\end{array}$ & $\begin{array}{l}4,33 \\
1,15\end{array}$ & $\begin{array}{l}F=0,83 \\
p=0,445\end{array}$ & $\begin{array}{l}F=1,45 \\
p=0,243\end{array}$ \\
\hline Arquétipo (*) & $\begin{array}{l}\text { média } \\
\mathrm{dp}\end{array}$ & $\begin{array}{l}4,01 \\
0,59\end{array}$ & $\begin{array}{l}4,35 \\
0,57\end{array}$ & $\begin{array}{l}4,29 \\
0,60\end{array}$ & $\begin{array}{l}4,00 \\
0,39\end{array}$ & $\begin{array}{l}2,75 \\
0,53\end{array}$ & $p=0,0001^{c}$ & $p=0,0001^{c}$ \\
\hline
\end{tabular}

(*) Esta variável não faz parte do cálculo da Manova. Teste pela Anova One Way.

$\left({ }^{a}\right)$ Resultados para análise envolvendo somente os tipos puros $(n=30)$.

(b) Resultados para análise envolvendo todos os casos $(\mathrm{n}=42)$.

(c) Pelo teste Tukey-B, somente o grupo regional possui diferença significativa ao nível de 0,05.

Fonte: dados primários da pesquisa.

Tal consideração está intimamente ligada a dois pressupostos adotados na presente pesquisa. O primeiro diz respeito à lógica de construção social ao reconhecer que os valores organizacionais, apesar de atuarem como mediadores da relação com o mundo institucional, também são constantemente influenciados por ele. A abordagem topo-base de difusão dos valores institucionais (Scott, 1994, 1995a) apresenta elementos para a compreensão da lógica de transformação das bases culturais internas em busca de legitimação com o contexto social mais amplo. Assim, os valores institucionalizados no âmbito social são difundidos para o conjunto das organizações. Já o segundo pressuposto relaciona essa dinâmica com a noção de estrutura. Nesse sentido, Ranson, Hinings e Greenwood (1980, p. 3) compreendem a estrutura como "veículo construído para refletir e facilitar significados", o que ressalta a sua interação com os valores organizacionais em 
uma lógica de mútua constituição, sendo ambos continuamente produzidos e recriados.

Nesse sentido, procurou-se complementar a análise verificando o nível de comprometimento dos dirigentes organizacionais com os valores integrantes do arquétipo de aprendizagem, conforme se pode visualizar na Tabela 2. Seguindo a direção teórica deste artigo, espera-se que empresas com contexto institucional de referência internacional favoreçam uma maior congruência entre os valores organizacionais e os valores do arquétipo de aprendizagem.

Tabela 2: Descrição dos Valores do Arquétipo de Aprendizagem

\begin{tabular}{|c|c|c|c|c|c|c|c|c|}
\hline Manova: Wilks, $p=0,459^{a} ; p=0,283^{b}$ & & $\begin{array}{c}\text { Amostra } \\
(n=42)\end{array}$ & $\begin{array}{l}\text { Internacional } \\
\quad(n=2)\end{array}$ & $\begin{array}{c}\text { Nac/Inter } \\
(n=12)\end{array}$ & $\begin{array}{c}\text { Nacional } \\
(n=25)\end{array}$ & $\begin{array}{l}\text { Regional } \\
(n=3)\end{array}$ & $\begin{array}{l}\text { Univariate } F- \\
\text { tests }^{a}\end{array}$ & $\begin{array}{l}\text { Univariate F- } \\
\text { tests } b\end{array}$ \\
\hline \multirow[t]{3}{*}{ Inovação e Mudança } & média & 4,53 & 4,08 & 4,60 & 4,55 & 4,44 & $F=0,31$ & $F=0,23$ \\
\hline & & 0,82 & 0,59 & 0,88 & 0,85 & 0,51 & $p=0,737$ & $p=0,876$ \\
\hline & cv & 0,180 & 0,144 & 0,192 & 0,187 & 0,115 & & \\
\hline \multirow[t]{3}{*}{ Proatividade } & média & 4,76 & 5,50 & 4,70 & 4,76 & 4,56 & $F=0,82$ & $F=0,61$ \\
\hline & & 0,82 & 0,24 & 0,77 & 0,90 & 0,19 & $p=0,449$ & $p=0,615$ \\
\hline & $\mathrm{cv}$ & 0,172 & 0,043 & 0,165 & 0,190 & 0,042 & & \\
\hline \multirow[t]{3}{*}{ Pluralismo } & média & 4,69 & 5,19 & 4,62 & 4,71 & 4,42 & $F=0,47$ & $F=0,37$ \\
\hline & & 0,82 & 0,80 & 0,75 & 0,88 & 0,88 & $p=0,632$ & $p=0,774$ \\
\hline & $\mathrm{cv}$ & 0,175 & 0,153 & 0,162 & 0,186 & 0,199 & & \\
\hline \multirow[t]{3}{*}{ Compartilhamento } & média & 5,67 & 5,83 & 5,67 & 5,69 & 5,44 & $F=0,21$ & $F=0,12$ \\
\hline & & 0,75 & 0,24 & 0,91 & 0,73 & 0,69 & $p=0,814$ & $p=0,949$ \\
\hline & cv & 0,133 & 0,040 & 0,160 & 0,129 & 0,127 & & \\
\hline \multirow[t]{3}{*}{ Flexibilidade } & média & 3,21 & 3,69 & 3,35 & 3,10 & 3,25 & $F=0,85$ & $F=0,79$ \\
\hline & $\mathrm{dp}$ & 0,64 & 0,44 & 0,70 & 0,64 & 0,50 & $p=0,437$ & $p=0,506$ \\
\hline & cv & 0,200 & 0,120 & 0,208 & 0,207 & 0,154 & & \\
\hline \multirow[t]{3}{*}{ Capacitação } & média & 3,86 & 3,88 & 4,54 & 3,66 & 2,83 & $F=1,09$ & $F=3,97$ \\
\hline & $\mathrm{dp}$ & 1,00 & 0,18 & 0,77 & 0,96 & 1,15 & $p=0,350$ & $p=0,015$ \\
\hline & $\mathrm{cv}$ & 0,259 & 0,046 & 0,170 & 0,261 & 0,408 & & \\
\hline \multirow[t]{3}{*}{ Perspectiva Sistêmica } & média & 4,91 & 6,38 & 4,92 & 4,97 & 3,33 & $F=4,43$ & $F=3,23$ \\
\hline & $\mathrm{dp}$ & 1,19 & 0,18 & 0,97 & 1,14 & 1,53 & $p=0,022$ & $p=0,033$ \\
\hline & $\mathrm{cv}$ & 0,243 & 0,028 & 0,198 & 0,230 & 0,458 & & \\
\hline \multirow[t]{3}{*}{ Valores $(*)$} & média & 4,52 & 4,93 & 4,63 & 4,49 & 4,04 & $p=0,1571^{c}$ & $p=0,1995^{c}$ \\
\hline & $\mathrm{dp}$ & 0,51 & 0,21 & 0,48 & 0,52 & 0,35 & & \\
\hline & $\mathrm{cV}$ & 0,112 & 0,043 & 0,104 & 0,116 & 0,087 & & \\
\hline
\end{tabular}

(*) Esta variável não faz parte do cálculo da Manova. Teste pela Anova One Way.

( $\left.{ }^{a}\right)$ Resultados para análise envolvendo somente os tipos puros $(\mathrm{n}=30)$.

(b) Resultados para análise envolvendo todos os casos $(\mathrm{n}=42)$.

(c) Pelo teste Tukey-B, somente o grupo regional possui diferença significativa ao nível de 0,05 .

Fonte: dados primários da pesquisa.

Em se tratando dos valores do arquétipo observou-se, comparativamente com os outros clusters, que embora o grupo com contexto institucional de referência regional tenha apresentado as menores médias, em termos absolutos esses escores não foram baixos. O mesmo pôde ser verificado com relação aos grupos com contexto institucional de referência nacional e com contexto institucional de referência nacional/internacional. Tal constatação indica que os dirigentes, de modo 
geral, possuem posição de concordância conceitual com os valores do arquétipo de aprendizagem, independentemente do contexto institucional de referência da empresa.

A representação no Gráfico 1 permite visualizar de forma mais clara os resultados obtidos: à medida que o contexto institucional de referência das empresas em relação aos três níveis ambientais definidos no Quadro 3 se restringe, a presença de atributos estruturais do arquétipo de aprendizagem também reduz a sua importância. Já no que concerne aos valores essa tendência também ocorre, mas em amplitude muito menor, de modo que os grupos apresentam escores médios muito próximos, com todos eles voltados para a concordância com os valores do arquétipo de aprendizagem. Dispostos dessa maneira, tais resultados chamam a atenção para um novo problema: a inconsistência entre estrutura e valores naquelas empresas enquadradas nos grupos com contexto institucional de referência não congruente com o contexto ambiental efetivo.

\section{Gráfico 1: Relação entre Contexto Institucional de Referência, Características e Valores do Arquétipo para os Tipos Puros (*)}

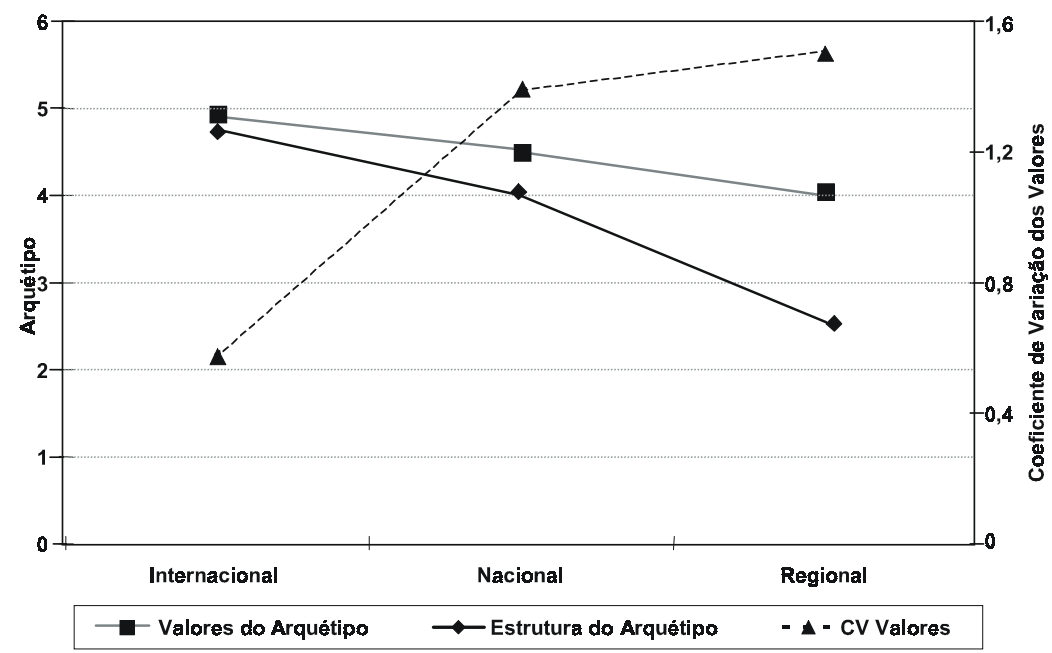

(*) Incluiu-se somente variáveis estruturais que apresentaram diferenças significativas entre os grupos. O coeficiente de variação corresponde à soma dos coeficientes para cada um dos valores do arquétipo, individualmente.

Fonte: dados primários da pesquisa.

A explicação para tal resultado pode ser apresentada a partir da observação dos coeficientes de variação calculados para os valores do arquétipo. Verificouse que, em comparação com os demais grupos, as empresas enquadradas no grupo com contexto institucional de referência internacional apresentaram um 
coeficiente de variação menor que as demais, indicando um grupo dirigente altamente concordante com os valores do arquétipo.

Tal evidência indica que organizações com contexto institucional de referência convergente com o contexto ambiental efetivo possuem configuração interna compatível entre valores e estrutura, constituindo um arquétipo condizente com esse nível. Dessa forma, o grau de coesão observado por meio dos coeficientes de variação entre os valores dos dirigentes das empresas, classificadas no grupo com contexto institucional de referência internacional, indica que eles se apresentam mais sedimentados internamente. Por conseguinte, propiciam a legitimação da estrutura que já está consolidada simbolicamente na empresa. Adicionalmente, por não expressar forte contradição com a situação ambiental, a emergência de uma nova condição ocorre de forma suave, já que não representa distorção abrupta com o esquema interpretativo prevalecente na empresa.

Em contrapartida, nos demais grupos pode-se inferir que, pelo fato de se encontrarem mais afastados das características e valores associados ao contexto efetivo do setor, as condições impostas pelo ambiente em direção a uma estrutura segundo o arquétipo de aprendizagem apenas criam um impulso para a mudança, a qual só ocorrerá efetivamente à medida que o sistema de interpretação das empresas acomodar essa nova condição. Tal constatação encontra suporte nos argumentos de Bartunek (1984). Talvez por isso se tenha verificado alguma tensão entre os valores do grupo dirigente, reflexo de grau menor de concordância, que contribuíram para uma configuração estrutural menos compatível com as características do arquétipo da organização que aprende. A observância dos coeficientes de variação desses clusters, indica a propensão em haver maior desacordo dos dirigentes do nível estratégico em relação aos valores do arquétipo de aprendizagem naquelas empresas que se situam fora do grupo com contexto institucional de referência internacional.

Por outro lado, dada a propensão de concordância com os valores associados ao arquétipo de aprendizagem, pode-se ainda explicar a inconsistência entre os valores e a estrutura de maneira diferente, mas complementar à anterior. Os resultados apresentados parecem indicar que as empresas dos diversos grupos conferiram aprovação institucional ao arquétipo de aprendizagem. É possível argumentar que há indícios de um fenômeno institucional em processo, de modo que a propagação da imagem da organização que aprende, cujas características seriam adequadas à atual realidade, foi vista como apropriada pelos dirigentes organizacionais, refletindo-se no discurso em favor dos valores da aprendizagem. Tal interpretação justificaria os altos escores encontrados nas médias dos valores do arquétipo de aprendizagem, independentemente da estrutura da empresa.

No sentido proposto por Greenwood e Hinings (1993), pode-se supor, também, 
que nessas empresas exista um comprometimento competitivo em relação aos valores de dois arquétipos diferentes: o atualmente presente na organização e o de aprendizagem. Tal possibilidade permite considerar que pode estar em andamento uma gradual mudança de perspectiva dos dirigentes organizacionais em direção a um arranjo alternativo, que se sustenta em base interpretativa diferente, mas que ainda não surtiu reflexos sobre a estrutura.

O contexto institucional de referência, portanto, parece intervir fortemente entre os valores ambientais e a estrutura, quando se trata da aprendizagem organizacional. De tal forma que, se restrito, não valoriza efetivamente os requisitos da esfera institucional mais ampla, transpondo-os para a realidade organizacional de forma inadequada, com claras limitações na congruência entre valores e estrutura de aprendizagem organizacional. Já aquelas organizações com contexto institucional de referência mais amplo de fato reconhecem mais nitidamente as implicações do ambiente, tornando o processo de transposição dos requisitos ambientais para o interior da organização menos difuso e mais consistente, cujo resultado seria uma estrutura efetivamente enquadrada sobre determinado arquétipo. Essa dinâmica pode ser resumida na seguinte afirmação: as organizações estão sujeitas a um processo contínuo de representação e externalização do plano institucional que, por meio do compartilhamento de valores entre seus integrantes, define o seu escopo de ação.

\section{Conclusão}

No presente artigo adotou-se a noção de que a aprendizagem organizacional como fenômeno próprio só pode ser compreendida no nível agregado. Assim, procurou-se ampliar o entendimento do constructo aprendizagem organizacional, a partir de uma perspectiva integradora que envolve fatores institucionais, cognitivos e culturais.

A análise dos dados demonstrou que os valores organizacionais encontram-se fortemente associados a valores ambientais do contexto institucional de referência das empresas, tal como é visualizado e interpretado pelo grupo de dirigentes que detém o domínio da organização. Nesse sentido, empresas com contexto institucional de referência internacional, que é coincidente com o ambiente efetivo do setor de alimentos, apresentaram alto grau de convergência com os valores subjacentes e as características estruturais e de sistema do arquétipo de aprendizagem. Por outro lado, as empresas com contexto institucional de referência mais restrito do que o ambiente efetivo de competição do setor revelaram menor predisposição para a aprendizagem organizacional. 
Tais resultados, que corroboram as hipóteses deste estudo, parecem fornecer suporte para o quadro teórico utilizado. Em especial no que concerne à relação entre valores ambientais do contexto institucional de referência da organização e atributos estruturais do arquétipo de aprendizagem.

Ao se partir do pressuposto de que os valores ambientais estão dispostos de maneira tal que não são percebidos e interpretados da mesma forma pelos dirigentes organizacionais, atribuiu-se relevância ao conceito de contexto institucional de referência. Este conceito permitiu a classificação das empresas em grupos de acordo com a interpretação de seus dirigentes sobre o nível de análise ambiental a ser considerado como referência. "Isso sugere que o conjunto de significados internamente consolidados também rege a escolha da esfera de atuação sobre a qual a organização pretende operar" (Machado-da-Silva e Fonseca, 1996, p. 110). Assim, as organizações procuram estruturar-se e definir estratégias de ação em conformidade com o que por elas é visualizado e valorizado, isto é, segundo o seu quadro de referência cultural e relacional.

Constatação deste tipo permite que se faça associação com o arquétipo de aprendizagem. A lógica de concepção de um arquétipo provém de um conjunto integrado de estrutura e valores num sentido lógico e interdependente. Assim, partindo-se do pressuposto de que o arquétipo de aprendizagem está imbricado com os valores do contexto ambiental efetivo de competição de determinado setor, conclui-se que uma organização apresenta maior predisposição para a aprendizagem se articular esses valores internamente em um sistema de interpretação compatível com os elementos associados a esse contexto.

À luz do referencial teórico utilizado neste estudo e dos resultados alcançados pela pesquisa empírica, torna-se possível conceber um modelo de análise da aprendizagem organizacional que possa orientar futuras investigações. Tal modelo considera três componentes fundamentais: (1) a relação entre valores ambientais e organizacionais; (2) a própria articulação dos valores organizacionais nos diversos níveis e segmentos da organização; (3) a relação entre valores e estrutura no processo de mútua constituição. Ao se considerar esses três componentes, o modelo enfatiza a relação entre o domínio institucional e o domínio da ação organizacional.

Nesse sentido, define-se a aprendizagem organizacional como o processo que, sustentado por movimentos internos de construção de significados intersubjetivos, se configura em uma dinâmica de contínua representação e externalização do plano institucional que orienta o domínio da ação organizacional. Cabe ressaltar que essa representação reflete o duplo sentido associado ao termo aprendizagem organizacional, o qual esteve presente neste trabalho. Primeiro, a aprendizagem pode ser compreendida como o atributo a ser aprendido: o delineamento de 
um arquétipo denota essa propriedade. Segundo, a aprendizagem pode ser vista como processso, ou seja, como o processo de aprender. Sugere-se que a amplitude do constructo envolva esse duplo sentido, de atributo e de processo, seguindo a expressão de dualidade da estrutura de Giddens (1989), na qual essas dimensões da aprendizagem possam ser articuladas enquanto meio e resultado recursivamente construídos.

Enquanto atributo, a aprendizagem é conceito construído institucionalmente, com propriedades estruturais decorrentes da evolução histórica do relacionamento entre entidades sociais e que, portanto, pode ter o seu perfil alterado ao longo do tempo. Como processo, compreende a relação entre o plano institucional e o plano organizacional, seguindo a lógica de apreensão do mundo institucional com base na construção de conceitos, os quais se aplicam na constituição das estruturas organizacionais. Esse duplo envolvimento do conceito de aprendizagem organizacional significa que as organizações se sustentam em elementos estruturais de um sistema social mais amplo, que são por elas reproduzidos. Assim, as propriedades estruturais da aprendizagem são o meio e o resultado da conduta organizacional, constituindo sistemas de interação de maneira recursiva ao atuar tanto sobre o domínio da ação quanto no domínio institucional.

\section{Nota}

${ }^{1}$ Principais fontes consultadas para construção do arquétipo de aprendizagem organizacional: Argyris e Schön (1978, 1996), Hedberg (1981), Morgan e Ramirez (1983), Fiol e Lyles (1985), Levitt e March (1988), Garvin (1993), Kim (1993), Nonaka e Takeuchi (1997), Senge (1998).

\section{Referéncias Bibliográficas}

ABIA.

O mercado brasileiro de alimentos industrializados. São Paulo : Associação Brasileira das Indústrias da Alimentação, Departamento Econômico, 1999.
ARGYRIS, C.;

SCHÖN, D. A.

Organizational learning : a theory of action perspective. Reading, MA : Addison-Wesley, 1978. 
Organizational learning II : theory, method, and practice. Reading, MA : Addison-Wesley, 1996.

BARTUNEK, J. M.

Changing interpretative schemes and organizational restructuring : the example of a religious order. Administrative Science Quarterly, v. 29, n. 3, p. 355-372, 1984.

BELIK, W.

Agroindústria e reestruturação industrial no Brasil : elementos para uma avaliação. In: RAMOS, P.; REYDON, B. P (Orgs.). Agropecuária e agroindústria no Brasil : ajuste, situação atual e perspectivas. Campinas : Abra, 1995.

BERGER, P. L.;

LUCKMANN, T.

The social construction of reality : a treatise in the sociology of knowledge. New York : Doubleday Anchor Books, 1967.

BEYER, J. M.

Ideologies, values, and decision making in organizations. In: NYSTRON, P. C.; STARBUCK, W. H. (Eds.). Handbook of organizational design. New York : Oxford University Press, 1981. p. 166-202.
CARMO, M. S.

(Re)estruturação do sistema agroalimentar no Brasil : a diversificação da demanda e a flexibilidade da oferta. São Paulo : IEA, 1996.

COOK, S. D. N.;

YANOW, D.

Culture and organizational learning. In: COHEN, M. D.; SPROULL, L. S. (Eds.). Organizational learning. London : Sage Publications, 1996. p. 430-459.

COOPER, D. J. et al.

Sedimentation and transformation in organizational change : the case of Canadian law firms. Organization Studies, v. 17, n. 4, p. 623-647, 1996.

CROSSAN, M. M. et al.

Learning within organization. Working paper series, n. 94, 1994.

DAFT, R. L.;

WEICK, K. E.

Toward a model of organizations as interpretation systems. Academy of Management Studies, v. 9, n. 2, p. 284-295, 1984. 
DIMAGGIO, P. J.;

POWELL, W. W.

The iron cage revisited : institutional isomorphism and collective rationality in organizational fields. American Sociological Review, v. 48, n. 2 , p. 147-160, 1983.

DODGSON, M.

Organizational learning : a review of some literatures. Organization Studies, v. 14, n. 3, p. 375-394, 1993.

EASTERBY-SMITH, M.

Disciplines of organizational learning : contributions and critiques. Human Relations, v. 50, n. 9, p. 1085-1113, 1997.

\section{ENZ, C. A.}

The role of value congruity in intraorganizational power. Administrative Science Quarterly, v. 33, p. 284-304, 1988.

FARINA, E. M. M. Q;

AZEVEDO, P. F.;

SAES, M. S. M.

Competitividade : mercado, estado e organizações. São Paulo : Singular, 1997.
FERRAZ, J. C.;

KUPFER, D.;

HAGUENAUER, L.

Made in Brazil : desafios competitivos para a indústria. Rio de Janeiro : Campus, 1997.

FIOL, C.;

LYLES, M.

Organizational learning. Academy of Management Review, v. 10, p. 803-813, 1985.

GARVIN, D. A.

Building a learning organization. Harvard Business Review, p. 78-91, July/Aug. 1993.

GIDDENS, A.

Sociologia : uma breve porém crítica introdução. Rio de Janeiro : Zahar, 1984.

A constituição da sociedade. São Paulo : Martins Fontes, 1989.

GREENWOOD, R.;

HININGS, C. R.

Understanding strategic change : the contribution of archetypes. Academy of Management Journal, v. 36, n. 5, p. 1052-1081, 1993. 
HEDBERG, B.

How organizations learn and unlearn. In: NYSTRON, P.; STARBUCK, W. (Eds.). Handbook of organizational design. New York : Oxford University Press, 1981. p. 3-27.

HININGS, C. R.;

GREENWOOD, R.

The dynamics of strategic change. New York : Blackwell, 1988.

KIM, D. H.

The link between individual and organizational learning. Sloan Management Review, p. 37-50, Fall 1993.

LEVITT, B.;

MARCH, J.

Organizational learning. Annual Review of Sociology, v. 14, p. 319-340, 1988.

MACHADO-DA-SILVA, C. L.; FERNANDES, B. H. R.

Mudança ambiental e reorientação estratégica : estudo de caso em instituição bancária. Revista de Administração de Empresas, v. 38, n. 4, p. 46-56, out./dez. 1998.

MACHADO-DA-SILVA, C. L.; FONSECA, V. S. DA.

Homogeneização e diversidade organizacional : uma visão integrativa. In: XVII ENCONTRO ANUAL DA ANPAD (1993 : Salvador). Anais... Salvador : ANPAD, 1993. v. Organizações.

Competitividade organizacional : uma tentativa de reconstrução analítica. Organizações e Sociedade, v. 4, n. 1, p. 97-114, 1996.

MACHADO-DA-SILVA, C. L.;

FONSECA, V. S. DA.;

FERNANDES, B. H. R.

Mudança e estratégia nas organizações : perspectivas cognitiva e institucional. In: VIEIRA, M. M. F.; OLIVEIRA, L. M. B. DE (Orgs.). Administração contemporânea : perspectivas estratégicas. São Paulo : Atlas, 1999a. p. 102-118.

Um modelo e quatro ilustrações : em análise a mudança nas organizações. In: XXIII ENCONTRO ANUAL DA ANPAD (1999 : Foz do Iguaçu). Anais Eletrônicos... Foz do Iguaçu : ANPAD, 1999b.

Cognição e institucionalização na dinâmica da mudança em organizações. In: RODRIGUES, S. B.; CUNHA, M. P. (Orgs.). Estudos organizacionais : novas perspectivas na administração de empresas - uma coletânea lusobrasileira. São Paulo : Iglu, 2000. p. 123-150. 
MARTINELLI JR., O.

A mudança tecnológica na indústria agroalimentar : algumas observações. Análise, v. 8, n. 1, p. 95-106, 1997.

MEYER, J. W.;

ROWAN, B.

Institutional organizations : formal structure as myth and ceremony. American Journal of Sociology, v. 83, n. 2, p. 340-363, 1977.

MORGAN, G.;

RAMIREZ, R.

Action learning : a holographic metaphor for guiding social change. Human Relations, v. 37, n. 1, p. 1-28, 1983.

NONAKA, I.;

TAKEUCHI, $\mathrm{H}$.

Criação de conhecimento na empresa : como as empresas japonesas geram a dinâmica da inovação. Rio de Janeiro : Campus, 1997.

RANSON, S.;

HININGS, B.;

GRENNWOOD, R.

The structuring of organizational structures. Administrative Science Quarterly, v. 25, n. 1, p. 1-17, 1980.
SCOTT, W. R.

Unpacking institutional arguments. In: POWELL, W. W.; DIMAGGIO, P. J. (Eds.). The new institutionalism in organizational analysis. Chicago : University of Chicago Press, 1991. p. 164-182.

Organizations : rational, natural and open systems. 3. ed. Englewood Cliffs : Prentice Hall, 1992.

Institutions and organizations. In: SCOTT, W. R.; MEYER, J. W. (Eds.). Institutional environments and organizations : structural complexity and individualism. London : Sage Publications, 1994. p. 55-80.

Institutions and organizations. London : Sage Publications, 1995a.

Institutional theory and organizations. In: SCOTT, W. R.; CHRISTENSEN, S. (Eds.). The institutional construction of organizations : international and longitudinal studies. London: Sage Publications, 1995b. p. xi-xxiii.

\section{SENGE, P.}

A quinta disciplina : arte e prática da organização de aprendizagem. São Paulo : Best Seller, 1998. 
TSANG, E. W. K.

Organizational learning and the learning organization : a dichotomy between descriptive and prescriptive research. Human Relations, v. 50, n. 1, p. 73-89, 1997.

\section{VIEIRA, L. F.}

Tecnologia agroalimentaria. In: Programa cooperativo para el desarrollo tecnologico agropecuario del Cono Sur - el cambio global y el desarrollo tecnologico agropecuario e agroindustrial del Cono Sur : implicaciones para las INTA'S y el PROCISUR. Montevideo : PROCISUR, 1997. p. 77-87.

VIGLIO, E. C. B. L.

Indústria de alimentação : características e tendências para o ano
2000. Agroanalysis, p. 6-12, Sept. 1996.

WEICK, K.;

WESTLEY, F.

Organizational learning : affirming an oxymoron. In: CLEGG, S.; HARDY, C.; NORD, W. (Eds.). Handbook of organizational studies. London : Sage Publications, 1996. p. 440-458.

WILKINSON, J.

Competitividade da agroindústria brasileira. Agricultura em São Paulo, v. 42, n. 1, p. 27-56, 1995.

ZUCKER, L. G.

Organizations as institutions. In: BACHARACH, S. B. (Ed.). Research in the sociology of organizations. Greenwich : Jai Press, 1983. p. 1-47. 